\title{
Pregnancy-associated stroke -a systematic review of subsequent pregnancies and maternal health
}

\author{
Liisa Karjalainen ${ }^{1 *} \mathbb{D}$, Minna Tikkanen², Kirsi Rantanen ${ }^{1}$, Hannele Laivuori ${ }^{3,4}$, Mika Gissler $^{5,6}$ and Petra ljäs
}

\begin{abstract}
Background: Pregnancy-associated stroke is a rare but life-threatening event, with an estimated incidence of 30/ 100000 deliveries. Data on the risk of stroke recurrence and the risk of other adverse pregnancy outcomes are essential for adequate counselling and surveillance in subsequent pregnancies. The aim of this systematic review is to describe the implications of a pregnancy-associated stroke for the future health of these women.
\end{abstract}

Methods: We searched Ovid Medline, PubMed, Cochrane Library and CINAHL for articles published in 1980-2018. Articles including women with pregnancy-associated stroke and information on at least one of the following outcomes were included: 1) recurrence of stroke during subsequent pregnancy, 2) number and course of subsequent pregnancies and their outcomes and 3) subsequent cardiovascular health.

Results: Twelve articles were included in the review, with six providing information on subsequent pregnancies, four on subsequent maternal health and two on both. The included articles varied greatly in terms of study design, length of follow up and reported outcomes. We found 252 women with pregnancy-associated stroke for whom the outcomes of interest were reported: 135 women with information on subsequent pregnancies and 123 women with information on future health. In total, 55 pregnancies after stroke were found. In the majority of studies, the incidence of pregnancy complications was comparable to that of the general population. The risk of stroke recurrence during pregnancy was $2 \%$. Data on subsequent health of these women were limited, and the quality of the data varied between the studies.

Conclusions: Data on subsequent pregnancies and health of women with a history of pregnancy-associated stroke are limited. Further research on this topic is essential for adequate counselling and secondary prevention.

Keywords: Stroke, Pregnancy, Postpartum period, Puerperium, Pregnancy-associated stroke, Follow-up, Recurrence, Subsequent pregnancies, Pregnancy outcome, Future health, Cardiovascular disease

\section{Background}

A stroke during pregnancy or puerperium is a rare event, but markedly affects the future life of the woman and her family. Pregnancy-associated stroke (PAS) accounts for up to $15 \%$ of maternal deaths [1]. The reported incidence of PAS and the distribution of stroke subtypes, ischaemic stroke (IS), intracerebral haemorrhage (ICH), subarachnoid haemorrhage (SAH) and cerebral venous thrombosis $(\mathrm{CVT})$, varies greatly due to different inclusion criteria

\footnotetext{
* Correspondence: liisa.karjalainen@helsinki.fi

${ }^{1}$ Department of Neurology, University of Helsinki and Helsinki University Hospital, Biomedicum Helsinki, P.O. Box 700, FI-00029 HUS Helsinki, Finland Full list of author information is available at the end of the article
}

and study designs. A recent meta-analysis reported an incidence of 30 strokes per 100,000 deliveries among all pregnancies [2]. The incidence of PAS varies depending on gestational age, with the greatest risk observed during the third trimester, delivery and the early postpartum period $[3,4]$. The latest studies indicate an increase in the PAS incidence, primarily as a result of an increase in hypertensive disorders of pregnancy and cardiac disease in pregnant women $[5,6]$.

Pregnancy and postpartum period increase the stroke risk compared to non-pregnant time. The estimated incidence of stroke during reproductive age is $10-20$ per 100,000 person-years $[7,8]$ and during pregnant and

(c) The Author(s). 2019 Open Access This article is distributed under the terms of the Creative Commons Attribution 4.0 International License (http://creativecommons.org/licenses/by/4.0/), which permits unrestricted use, distribution, and 
puerperal time 34 per 100,000 person-years (assuming the duration of pregnancy to be 40 weeks and defining puerperium as 6 weeks postpartum). Underlying diseases such as prothrombotic conditions, heart disease and anomalies of cerebral vasculature are risk factors for stroke also during pregnancy [9-12], while women with PAS are less likely to have conventional risk factors than non-pregnant women who suffer a stroke at the same age $[13,14]$. Pregnancy-related increase in stroke risk is thought to be a result of hemodynamic and coagulation system changes and pregnancy complications such as hypertensive disorders of pregnancy $[5,10,12,15-17]$, infections $[9,10,12]$, haemorrhage [10] and fluid and electrolyte imbalance [10, 12].

The outcome of stroke varies, but full recovery is possible, particularly in high-income countries. Since these women are of reproductive age, they often wish to conceive again. However, there is significant uncertainty surrounding the potential risks related to subsequent pregnancies and data on future health and long-term prognosis of these women are limited. The aim of this systematic review is to summarise the current knowledge on the subsequent pregnancies and future health of women with PAS and knowledge gaps in order to highlight the need for further research on the topic, essential for adequate counselling, pregnancy surveillance and secondary prevention throughout life in the future.

\section{Methods}

The literature search was conducted to identify studies reporting subsequent pregnancy outcomes and future cardiovascular health among women with a history of PAS in accordance with the Preferred Reporting Items for Systematic Reviews and Meta-Analysis (PRISMA) guidelines [18]. Relevant studies were identified covering the period from January 1980 to September 2018. We searched Ovid Medline, PubMed, Cochrane Library and CINAHL with the following terms: "stroke" or "cerebrovascular disorder" or specific stroke types separately and "pregnancy" or "postpartum period and "follow-up" or "recurrence" (see Additional file 1 for detailed search strategy). Reference lists from relevant articles were assessed in order to identify additional potential articles. Articles were included if they were published in English and included women with a history of pregnancy-associated or puerperal stroke. Of the stroke subtypes, we included IS, CVT, ICH and SAH. TIA was excluded. Articles were included if information on at least one of the following outcomes was provided: 1) recurrence of stroke during subsequent pregnancy, 2) number of subsequent pregnancies and their outcomes, 3) subsequent cardiovascular health. We excluded case reports and studies that limited their follow-up to the mortality and neurological recovery from the initial stroke.
Two authors (LK and PI) screened the titles and abstracts identified through the literature search. If eligibility remained unclear, the full article was reviewed. Disagreements were resolved through consensus. Data on the number of women with PAS, the number of women with PAS who had subsequent pregnancies, the number of pregnancies and their outcomes and complications, data on future health and the duration of the follow-up were extracted from the eligible articles.

\section{Results}

Figure 1 shows the flow diagram of the review process. We screened 615 records, 157 abstracts and 69 full-texts articles. Fifteen articles included women with PAS but did not provide sufficient data to identify the outcomes for the subgroup. All twelve included articles mainly reported outcomes of women with a history of non-pregnancy associated stroke (NPAS); only 3-33\% of women included in the cohorts had suffered a PAS. We found no studies focusing solely on women with PAS. Table 1 shows the details of the included studies [19-30]. We identified 252 cases with PAS who were included in the follow-up of the outcomes of interest: 135 women for subsequent pregnancies and 123 women for future health. CVT was the index event in 103/135 women (76\%) for whom subsequent pregnancies were reported.

\section{Course of subsequent pregnancies}

Of the 52 women with a history of PAS, 26 (50\%) had subsequent pregnancies; the studies by Ciron et al. [27] and Ferro et al. [23] were excluded from this calculation, as they do not report the number of women with subsequent pregnancies. The included studies reported a total of 55 pregnancies. Outcomes were reported in 42 of these pregnancies and they were the following: 32 live births $(76 \%)$, one foetal death (2\%), six miscarriages (14\%) and three induced abortions (7\%). Pregnancy complications were reported by all but one study [20]. The studies included 22 pregnancies that proceeded beyond 22 gestational weeks, i.e. excluding miscarriages and induced abortions. Of these 22 pregnancies, 17 (77\%) were uncomplicated/uneventful, three $(13 \%)$ were complicated by premature rupture of membranes $(<37$ gestational weeks), one (5\%) with pre-eclampsia and one (5\%) with foetal death. All of the complications reported were from the study by Coppage et al. [21]. The information on subsequent pregnancies and recurrence of stroke during pregnancy is presented in Table 2.

Alebeek et al. [28] assessed the occurrence of pregnancy complications in women with a history of stroke (IS or TIA) using the Dutch general population as a control group. The data for the women with a stroke history were self-reported and collected by telephone interview and the data to represent the general population was 


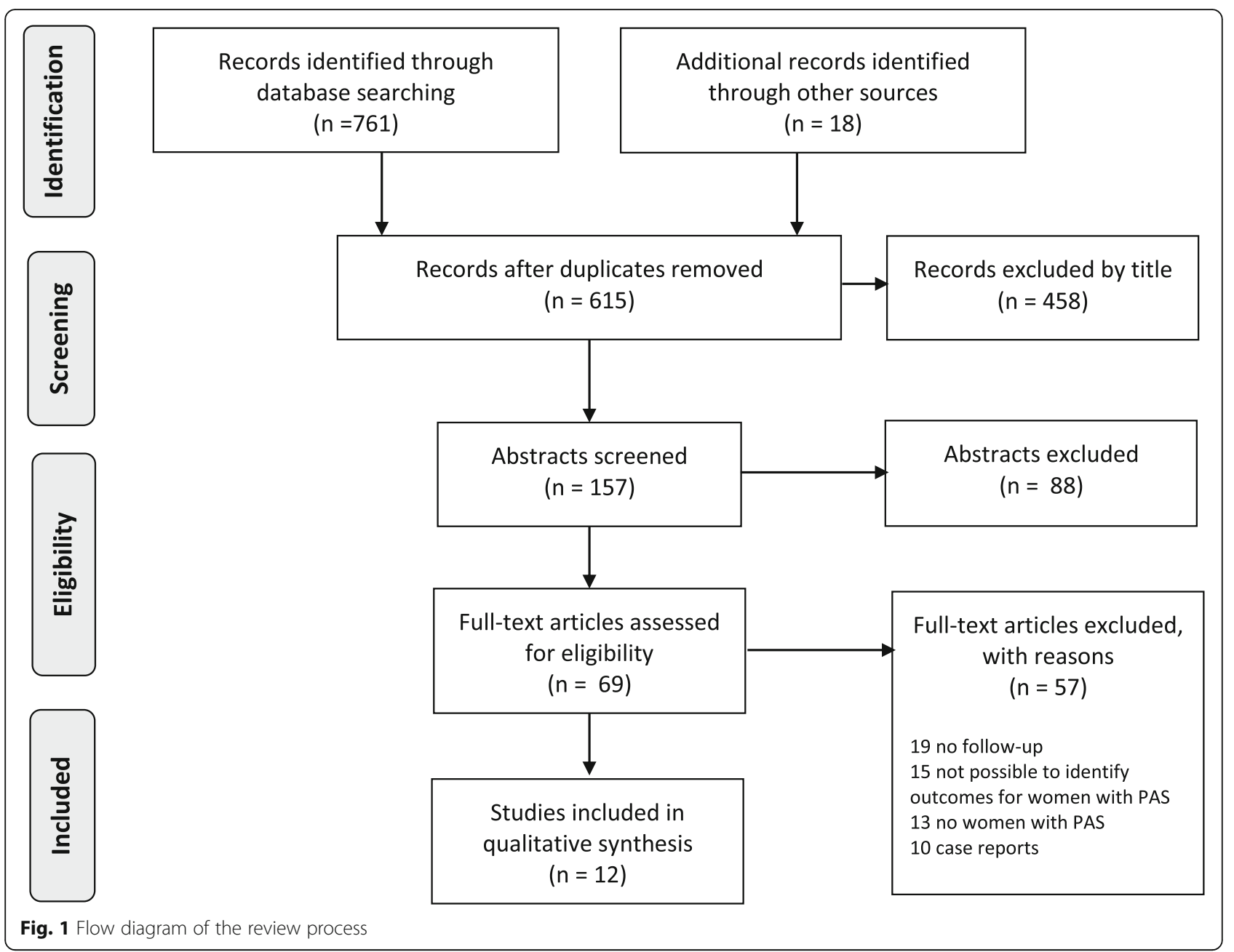

retrieved from the Dutch Perinatal Registry or Dutch HELLP foundation. The patients and controls were not matched on common risk factors for stroke and pregnancy complications (smoking, thrombophilia, hypertension, hypertensive disorders of pregnancy). In the subgroup of 20 women with PAS, $50 \%$ had experienced more than one miscarriage, $5 \%$ more than one foetal death, $25 \%$ gestational hypertension, $20 \%$ pre-eclampsia, $20 \%$ HELLP and $10 \%$ gestational diabetes. Substantially lower rates for the Dutch general population were reported: $13.5,0.9,11.7,0.5,0.5$ and $1.8 \%$, respectively. The study did not report the timing of the pregnancy outcomes in relation to the PAS, i.e. whether the complications occurred during the same pregnancy or not.

\section{PAS recurrence}

In the 55 pregnancies among women with a history of PAS, one $(2 \%)$ recurrent PAS occurred. This was a first trimester CVT in a woman with a history of CVT during pregnancy, sickle cell disease as an underlying condition. She used no prophylactic anticoagulant medication during the pregnancies following the primary CVT. The pregnancy was terminated. The study of Ciron et al. [27] did not provide details on the primary or the recurrent CVT (i.e. the location or extend of CVT or did CVT result in ischemic or haemorrhagic stroke). In addition, four articles reporting subsequent health of women after PAS $[19,22,28,30]$ stated there were no recurrent PAS.

\section{Subsequent health}

Table 3 presents information on the subsequent health of women with PAS. The articles varied greatly in terms of the diseases, outcomes included in follow-up and outcomes reported for women with PAS. Often all outcomes of interest were not specifically reported for women with PAS. The follow-up time varied from 6 months to 16 years after the index stroke. The initial type of stroke was not specified in 90/123 women (73\%) whose subsequent health was assessed and reported. During the follow-up there were altogether three vascular events, all ISs or TIAs from the study of Alebeek et al. [28]. The studies reporting long-term mortality 


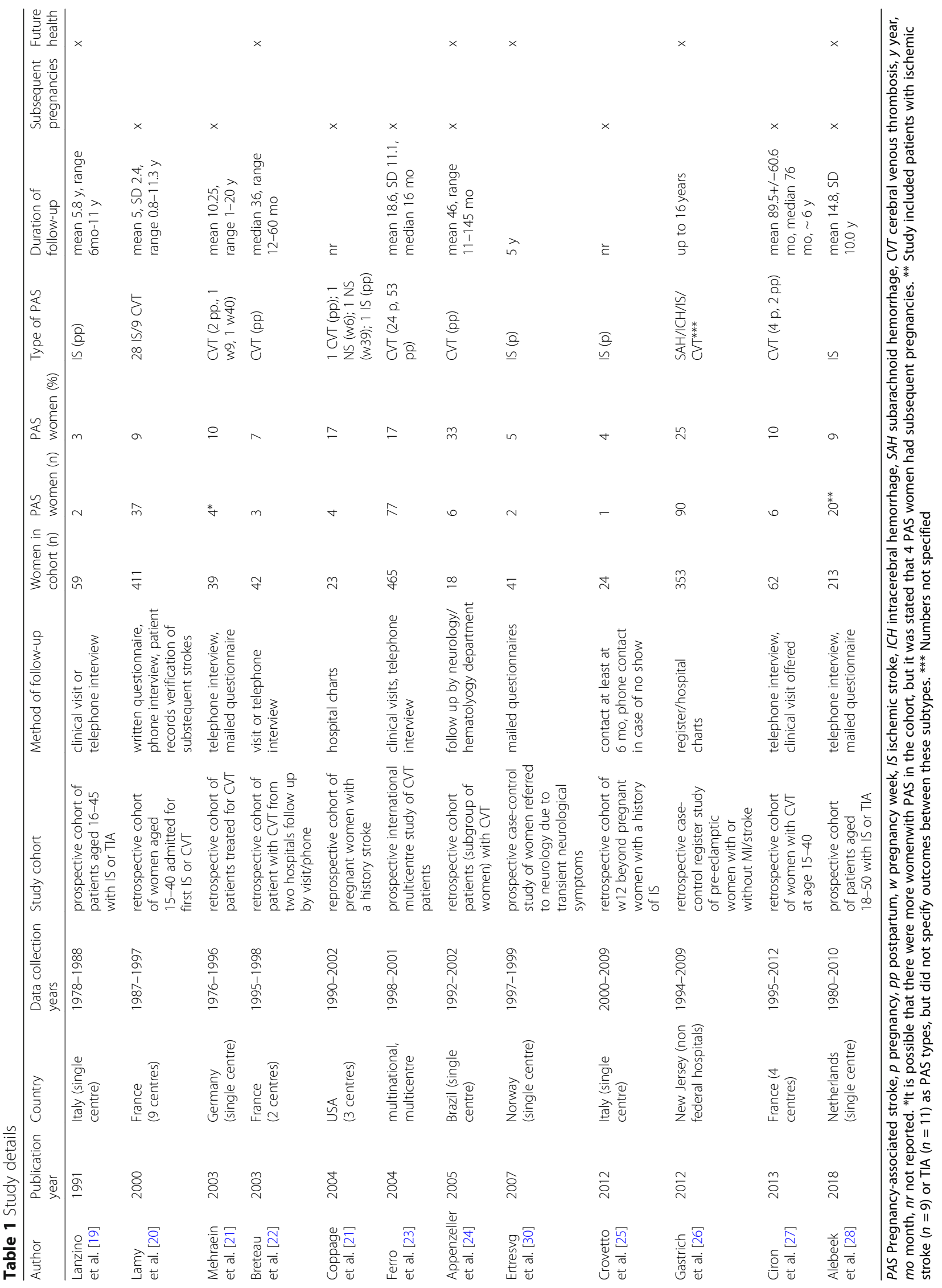




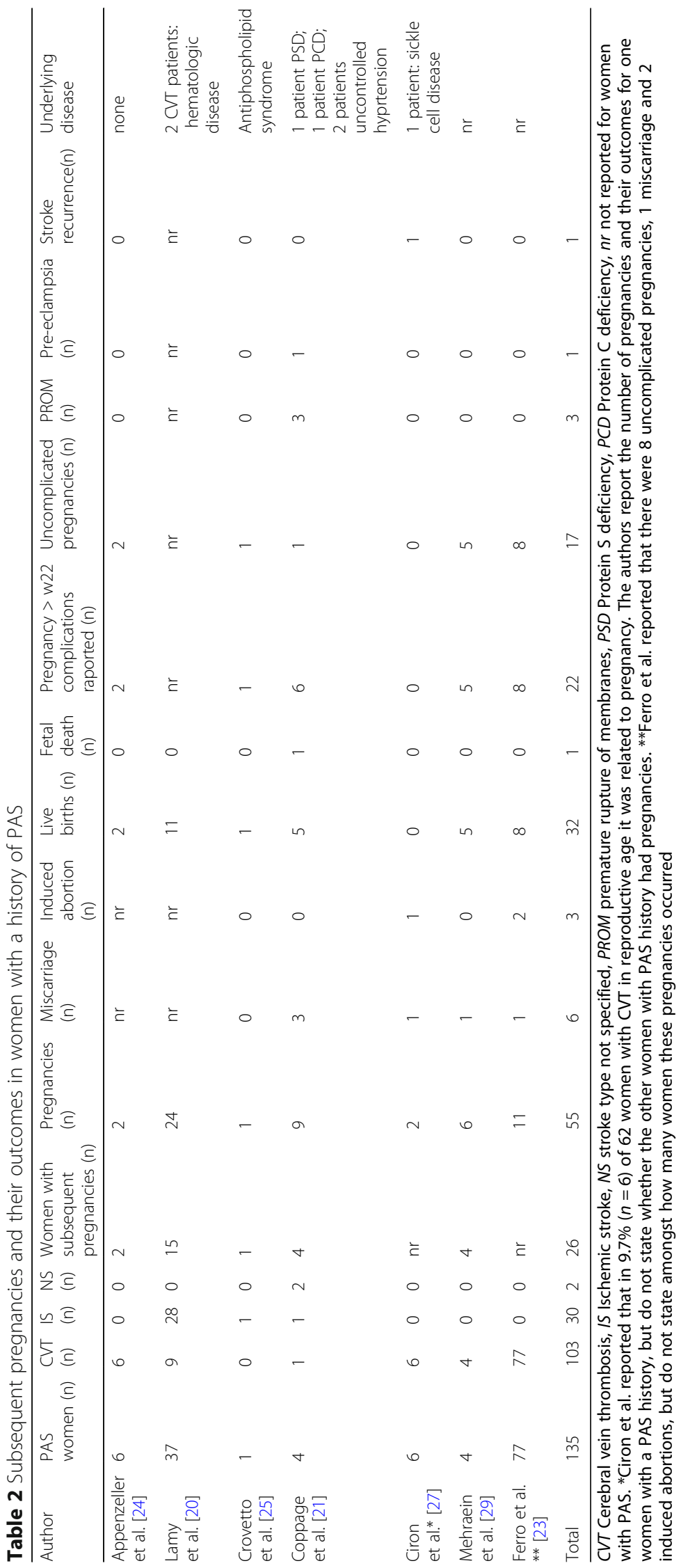


Karjalainen et al. BMC Pregnancy and Childbirth

(2019) 19:187

Page 6 of 10

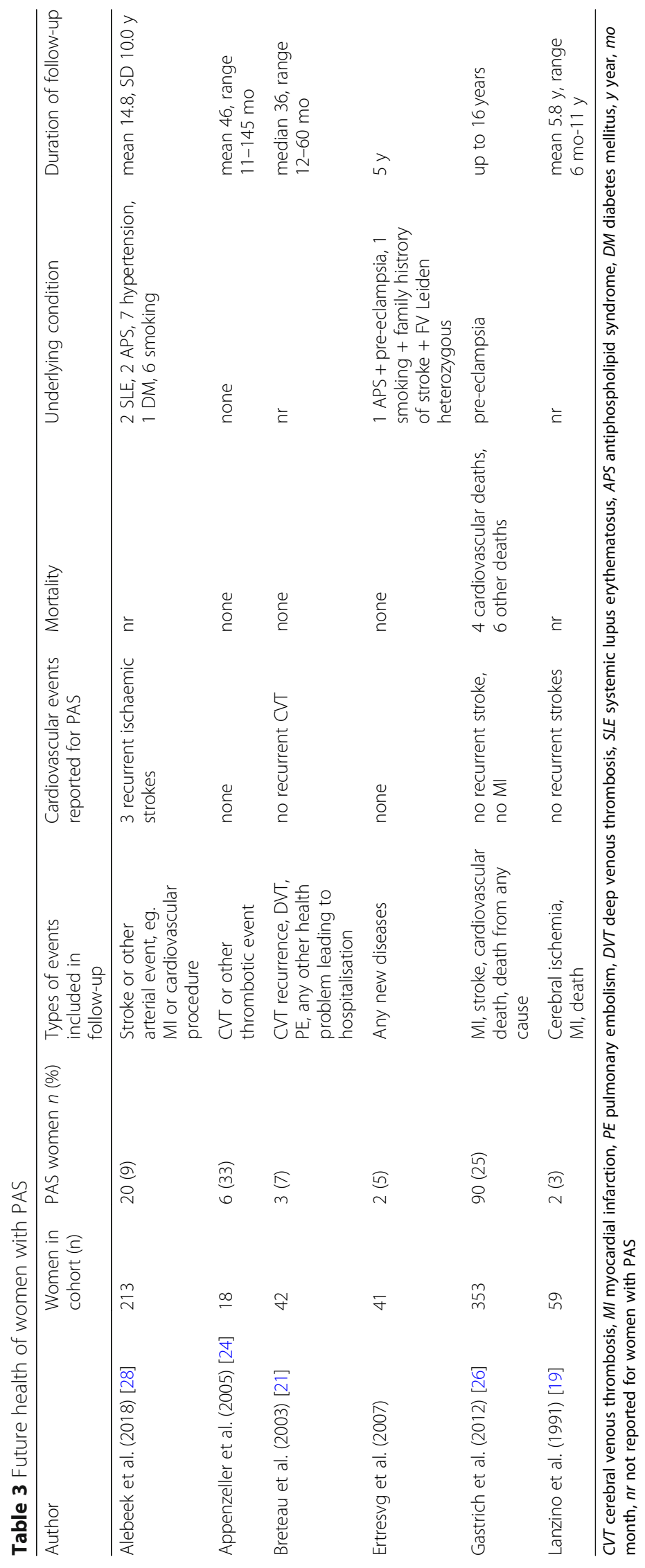


included 101 women and 10 (10\%) of these women died during the follow-up time up to 16 years, four from cardiovascular causes and six from other causes. All of these women were from the same cohort from Gastrich et al. [26] and had pre-eclampsia in association with the index stroke.

\section{Discussion}

During the past two decades knowledge on the incidence and risk factors of PAS has accumulated. By contrast, data on subsequent pregnancies and health of women with PAS are scattered, incompletely reported and limited information is available. The systematic review suggests that the incidence of pregnancy complications is comparable to that reported for women with a history of stroke (related or not related to pregnancy) $[20,21,27,31]$. Miscarriage seems to be as common among women with PAS as in the general population [32], but induced abortion is slightly more infrequent than in the general population [33]. This may reflect more careful family planning after PAS. One study reported less favourable obstetric prognosis, more severe pregnancy complications and more miscarriages and foetal deaths in women with a history of stroke than in the general population [28]. However, there are several methodological problems in the study. Most importantly, the ascertainment and data collection differed between the women with PAS and controls and they were not matched on risk factors for adverse pregnancy outcomes, such as smoking, hypertension and prothrombotic conditions, which all are also risk factors for stroke. Therefore, the findings may result from confounding risk factors. Also the frequencies of adverse pregnancy outcomes reported in the Dutch Perinatal Registry for the general populations are low and possibly under-reported [28], which may overestimate the differences between women with a stroke history and general population.

Based on limited number of published cases, the proportion of women with subsequent pregnancies after PAS was relatively high, $50 \%$. It is noteworthy that the percentage is based on less than half of the women with PAS included in the analysis of subsequent pregnancies, since two studies [23, 27] did not provide the data on number of women with subsequent pregnancies. This may overestimate the pregnancy rate. In previous studies, the proportion of young women with a history of stroke (related or not related to pregnancy) and subsequent pregnancies has ranged between 26 and 40\% [20, 27, 29, 31, 34]. Lamy et al. [20] found no difference in the number of subsequent pregnancies between women with a history of IS or CVT and age- and parity-matched controls from the general population. However, one-third of women with a history of stroke indicated that they would have wished for more pregnancies after their stroke and the most common causes for hesitation were concerns of recurrent stroke, medical advice against a new pregnancy and residual disability [20].

We found one recurrent PAS, CVT associated to sickle cell disease. Even though the number of patients is very limited, the recurrence of stroke during pregnancy or puerperium seems to be rare. The same applies to young stroke patients whose initial strokes have not been pregnancy related. The recurrence is mainly limited to women with underlying haematological diseases (such as protein $\mathrm{C}$ and $\mathrm{S}$ deficiency, sickle cell disease, antiphospholipid syndrome or systemic lupus erythematosus), cerebrovascular disease (arteriovenous malformations, aneurysms or Moyamoya disease) or maternal cardiac disease [20,21,31, 35, 36]. This is exemplified by a study by Fischer-Betz et al. [35] who reported pregnancy outcomes and recurrence of stroke during pregnancy for 20 women with antiphospholipid syndrome and a history of IS or TIA. The possible temporal connection of index stroke to pregnancy was not reported. Among subsequent pregnancies, stroke recurred in $15 \%$, while preeclampsia occurred in $34 \%$ of pregnancies and $8.7 \%$ of pregnancies resulted in neonatal death. Further, Soriano et al. [36] reported similar results in a study of thromboembolic complications of pregnancy and pregnancy outcomes in 12 women (15 pregnancies) with a history of stroke (IS, TIA and amaurosis fugax) and an underlying thrombophilic disorder who used LMWH and aspirin $100 \mathrm{mg}$ until 6 weeks' postpartum. Five of these 12 women $(42 \%)$ in the cohort had a history of PAS. Four patients $(33 \%)$ in this cohort had recurrent thromboembolic events (1 TIA, 1 amaurosis fugax in two subsequent pregnancies, 1 paresthesia of the left arm, 1 deep venous thrombosis and pulmonary embolism 3 weeks postpartum after discontinuing the preventive medication contrary to advice). Pre-eclampsia complicated five pregnancies (33\% of all), leading to preterm delivery in three pregnancies $(20 \%)$, of which one at 27 gestational weeks, resulting in neonatal death (7\% of newborns). Even though the proportion of PAS in this cohort was only $42 \%$, this may indicate that also PAS women with an underlying predisposing condition are at greater risk of recurrent PAS, other thrombotic events and adverse pregnancy outcomes than women whose index PAS has been cryptogenic.

The studies reporting subsequent health of women after PAS differed markedly in terms of settings and outcomes included in the follow-up. In $73 \%$ of the women whose future health was reported, the stroke subtype was not specified. During the follow-up ranging from 6 months to 16 years, altogether three ISs occurred among 123 women, i.e. $2 \%$ of the women suffered a NPAS. All of these women were from the same cohort of 20 women with PAS, the 
cumulative 20 -year risk being $15.6 \%$ when assessing this cohort separately. Hindfelt et al. [37] found 11\% of young IS survivors suffered a recurrence during the 13- to 26-year follow-up. The difference in their results compared with ours may be explained by a shorter follow-up time in the studies of our review, but also by a lower prevalence of traditional stroke risk factors among PAS women. Regarding mortality, we found a cumulative mortality rate of $10 \%$ after a follow-up ranging from 6 months to 16 years. This is in line with previous studies on the long-term prognosis of young patients with IS that have reported a cumulative 2- to 10 -year mortality of $10 \%$ [38, 39].

This study has a number of limitations. All studies included in this review were comprised of mainly women with a history of stroke that was not associated with pregnancy, the proportion of PAS varying from 3 to $33 \%$. Analyses were performed and results presented for the entire cohort instead of separating patients by the timing of the stroke, making it impossible to extract all outcomes included in the study for women with PAS specifically. The information about women with PAS, their subsequent pregnancies and their outcomes often had to be retrieved from tables in the articles or even from the discussion. A good example is the total number of pregnancies reported in the studies; two studies [20, 24] did not report miscarriages or induced abortions separately for women with PAS and Ciron et al. [27] reported outcomes of pregnancies for only one woman with PAS, but did not state whether other women with PAS had pregnancies and what their possible outcomes were. Therefore, the total number of pregnancies for women with PAS in the included studies may be more than 55 . Lamy at al. [20] did not report pregnancy complications, which may underestimate their incidence. The quality of information varied and was especially scant regarding future cardiovascular health. The length of the follow-up period was insufficient for evaluation of long-term cardiovascular outcome and mortality. These gaps in reporting reflect that women with PAS were not the main focus in these articles. Altogether, the limited number of cases and incomplete reporting causes uncertainty for the interpretation of result. However, the results revealed an evident gap in knowledge that warrants research on this topic, preferably in a population-based setting and with a sufficiently long follow-up.

\section{Conclusion}

PAS is a rare event with potentially devastating consequences for the everyday life of the young family. In the systematic review of subsequent pregnancies and health of these women, we found the data to be limited. In the context of published literature, half of women with a history of PAS have subsequent pregnancies, their outcomes are generally good and the stroke recurrence rate during subsequent pregnancies is low. This is reassuring when it comes to counselling women with a desire to conceive. An increased risk of adverse events and recurrence of PAS may be related to subsequent pregnancies of women with underlying diseases such as prothrombotic conditions, anomalies of cerebral vasculature and chronic heart disease. According to the results of this review, the prognosis of future health is similar for women with a history of PAS and patients with a history of stroke at young age, unrelated to pregnancy. However, further research on this topic is needed to improve pregnancy surveillance, preventive medication in subsequent pregnancies and secondary prevention throughout life.

\section{Additional file}

Additional file 1: Detailed search strategy for Ovid Medline, PubMed, CINHAL and Cochrane Library. (PDF $9 \mathrm{~kb}$ )

\begin{abstract}
Abbreviations
CVT: Cerebral venous thrombosis; HELLP: Haemolysis, elevated liver enzyme, low platelet count; ICH: Intracerebral haemorrhage; IS: Ischaemic stroke; LMWH: Low molecular weight heparin; PAS: Pregnancy-associated stroke; SAH: Subarachnoid haemorrhage; SLE : Systemic lupus erythematosus; TIA: Transient ischaemic attack
\end{abstract}

\section{Acknowledgements}

We thank the Department of Neurology, Helsinki University Hospital, for providing the facilities to carry out this research.

\section{Funding}

Stroke in Pregnancy and Puerperium in Finland (SIPP-Fin) received competitive state research financing of the expert responsibility area of Helsinki and Uusimaa Hospital District in 2017-2018. The funder had no role in the design of the study, collection, analysis, interpretation of data, or writing the manuscript.

\section{Availability of data and materials}

The detailed search strategy, providing the data for this systematic review, is included in the Additional file 1.

\section{Authors' contributions}

Conception and design: LK, PI, KR, MT. Database search, article screening and reviewing for eligibility: LK, PI. Analysis and interpretation of data: LK, PI. Writing, review and/or revision of the manuscript: $L K, P I, K R, M T, H L, M G$. All authors read and approved the final manuscript.

Ethics approval and consent to participate Not applicable.

Consent for publication Not applicable.

\section{Competing interests}

$\mathrm{HL}$ is a member of the Nordic Expert Group unconditionally supported by Gedeon Richter Nordics and has received an honorarium from Orion. All other authors declare no conflicts of interest.

\section{Publisher's Note}

Springer Nature remains neutral with regard to jurisdictional claims in published maps and institutional affiliations. 


\section{Author details}

'Department of Neurology, University of Helsinki and Helsinki University Hospital, Biomedicum Helsinki, P.O. Box 700, Fl-00029 HUS Helsinki, Finland. ${ }^{2}$ Department of Obstetrics and Gynaecology, University of Helsinki and Helsinki University Hospital, Helsinki, Finland. ${ }^{3}$ Medical and Clinical Genetics, University of Helsinki and Helsinki University Hospital and Institute for Molecular Medicine Finland, Helsinki Institute of Life Science, University of Helsinki, Helsinki, Finland. ${ }^{4}$ Department of Obstetrics and Gynaecology, Tampere University Hospital and Tampere University, Faculty of Medicine and Health Technology, Tampere, Finland. ${ }^{5}$ Department of Information Services, National Institute of Health and Welfare, Helsinki, Finland. ${ }^{6}$ Department of Neurobiology, Care Sciences and Society, Karolinska Institute, Stockholm, Sweden.

Received: 23 November 2018 Accepted: 13 May 2019 Published online: 28 May 2019

\section{References}

1. Say L, Chou D, Gemmill A, Tunçalp Ö, Moller A-B, Daniels J, et al. Global causes of maternal death: a WHO systematic analysis. Lancet Glob Heal. 2014;2(6):e323-33 Available from: https://www.sciencedirect.com/science/ article/pii/S2214109X1470227X. [cited 2018 Sep 21].

2. Swartz RH, Cayley ML, Foley N, Ladhani NNN, Leffert L, Bushnell C, et al. The incidence of pregnancy-related stroke: a systematic review and metaanalysis. Int J Stroke. 2017;12(7):687-97 Available from: http://www.ncbi.nlm. nih.gov/pubmed/28884652. [cited 2018 Feb 28].

3. Ban L, Sprigg N, Abdul Sultan A, Nelson-Piercy C, Bath PM, Ludvigsson JF, et al. Incidence of first stroke in pregnant and nonpregnant women of childbearing age: a population-based cohort study from England. J Am Heart Assoc. 2017;6(4) Available from: http://www.ncbi.nlm.nih.gov/ pubmed/28432074. [cited 2018 May 25].

4. Cantu-Brito C, Arauz A, Aburto Y, Barinagarrementeria F, Ruiz-Sandoval JL, Baizabal-Carvallo JF. Cerebrovascular complications during pregnancy and postpartum: clinical and prognosis observations in 240 Hispanic women. Eur J Neurol. 2011;18(6):819-25 Available from: http://doi.wiley.com/10.1111/ j.1468-1331.2010.03259.x. [cited 2018 May 22].

5. Leffert LR, Clancy CR, Bateman BT, Bryant AS, Kuklina EV. Hypertensive disorders and pregnancy-related stroke. Obstet Gynecol. 2015;125(1):124-31 Available from: http://www.ncbi.nlm.nih.gov/pubmed/25560114. [cited 2018 May 23].

6. Kuklina EV, Tong X, Bansil P, George MG, Callaghan WM. Trends in Pregnancy Hospitalizations That Included a Stroke in the United States From 1994 to 2007. Stroke. 2011;42(9):-2564 Available from: http://stroke. ahajournals.org/content/42/9/2564.abstract.

7. Petitti DB, Sidney S, Quesenberry CP, Bernstein A. Incidence of stroke and myocardial infarction in women of reproductive age. Stroke. 1997;28(2):2803 Available from: http://www.ncbi.nlm.nih.gov/pubmed/9040675. [cited 2018 Oct 4].

8. Tibæk M, Dehlendorff C, Jørgensen HS, Forchhammer HB, Johnsen SP, Kammersgaard LP. Increasing incidence of hospitalization for stroke and transient ischemic attack in young adults: a registry-based study. J Am Heart Assoc. 2016;5(5) Available from: http://www.ncbi.nlm.nih.gov/pubmed/ 27169547. [cited 2018 Oct 4].

9. Miller EC, Gallo M, Kulick ER, Friedman AM, Elkind MSV, Boehme AK. Infections and risk of Peripartum stroke during delivery admissions. Stroke. 2018;49(5): 1129 Available from: http://stroke.ahajournals.org/content/49/5/1129.abstract.

10. James $A H$, Bushnell $C D$, Jamison MG, Myers ER. Incidence and risk factors for stroke in pregnancy and the puerperium. Obstet Gynecol. 2005;106(3): 509-16 Available from: http://www.ncbi.nlm.nih.gov/pubmed/16135580. [cited 2018 Feb 13].

11. Bateman BT, Schumacher HC, Bushnell CD, Pile-Spellman J, Simpson LL, Sacco RL, et al. Intracerebral hemorrhage in pregnancy: frequency, risk factors, and outcome. Neurology. 2006;67(3):424-9 Available from: http:// www.ncbi.nlm.nih.gov/pubmed/8628469. [cited 2018 May 15].

12. Lanska DJ, Kryscio RJ. Risk factors for peripartum and postpartum stroke and intracranial venous thrombosis. Stroke. 2000;31(6):1274-82 Available from: http://www.ncbi.nlm.nih.gov/pubmed/10835444. [cited 2018 May 29].

13. Leffert LR, Clancy CR, Bateman BT, Cox M, Schulte PJ, Smith EE, et al. Treatment patterns and short-term outcomes in ischemic stroke in pregnancy or postpartum period. Am J Obstet Gynecol. 2016;214(6):723.e1723.e11 Available from: http://www.ncbi.nlm.nih.gov/pubmed/26709084. [cited 2018 May 28].
14. Miller EC, Gatollari HJ, Too G, Boehme AK, Leffert L, Elkind MSV, et al. Risk of pregnancy-associated stroke across age groups in New York state. JAMA Neurol. 2016;73(12):1461 Available from: http://www.ncbi.nlm.nih.gov/ pubmed/27775757. [cited 2018 May 21].

15. Scott CA, Bewley S, Rudd A, Spark P, Kurinczuk JJ, Brocklehurst P, et al. Incidence, risk factors, management, and outcomes of stroke in pregnancy. Obstet Gynecol. 2012;120(2, Part 1):318-24 Available from: http://www.ncbi. nlm.nih.gov/pubmed/22825091. [cited 2018 May 22].

16. Tang CH, Wu CS, Lee TH, Hung ST, Yang CYC, Lee CH, et al. Preeclampsiaeclampsia and the risk of stroke among Peripartum in Taiwan. Stroke. 2009; 40(4):1162-8 Available from: http://www.ncbi.nlm.nih.gov/pubmed/ 19228854. [cited 2018 May 22].

17. Brown DW, Dueker N, Jamieson DJ, Cole JW, Wozniak MA, Stern BJ, et al. Preeclampsia and the risk of ischemic stroke among young women: results from the stroke prevention in young women study. Stroke. 2006;37(4):1055-9 Available from: http://www.ncbi.nlm.nih.gov/pubmed/16484606. [cited 2018 May 23].

18. Moher D, Liberati A, Tetzlaff J, Altman DG. Preferred reporting items for systematic reviews and meta-analyses: the PRISMA statement. J Clin Epidemiol. 2009;62(10):1006-12 Available from: https://www.sciencedirect.com/science/ article/pii/S0895435609001796?via\%3Dihub. [cited 2018 Sep 13].

19. Lanzino G, Andreoli A, Di Pasquale G, Urbinati S, Limoni P, Serracchioli A, et al. Etiopathogenesis and prognosis of cerebral ischemia in young adults. A survey of 155 treated patients. Acta Neurol Scand. 1991;84(4):321-5 Available from: http://www.ncbi.nlm.nih.gov/pubmed/1772005. [cited 2018 Sep 10].

20. Lamy C, Hamon JB, Coste J, Mas JL. Ischemic stroke in young women: risk of recurrence during subsequent pregnancies. French study group on stroke in pregnancy. Neurology. 2000;55(2):269-74 Available from: http:// www.ncbi.nlm.nih.gov/pubmed/10908903. [cited 2018 May 30].

21. Coppage $\mathrm{KH}$, Hinton AC, Moldenhauer J, Kovilam O, Barton JR, Sibai BM. Maternal and perinatal outcome in women with a history of stroke; Available from: https://www.ncbi.nlm.nih.gov/pubmed/15167838. [cited 2018 Sep 10]

22. Breteau G, Mounier-Vehier F, Godefroy O, Gauvrit J-Y, Mackowiak-Cordoliani $M-A$, Girot $M$, et al. Cerebral venous thrombosis 3-year clinical outcome in 55 consecutive patients. J Neurol. 2003;250(1):29-35 Available from: http:// link.springer.com/10.1007/s00415-003-0932-4. [cited 2018 Sep 14].

23. Ferro JM, Canhão P, Stam J, Bousser M-G, Barinagarrementeria F. Prognosis of cerebral vein and Dural sinus thrombosis Results of the International Study on Cerebral Vein and Dural Sinus Thrombosis (ISCVT); 2004.

24. Appenzeller S, Zeller CB, Annichino-Bizzachi JM, Costallat LTL, Deus-Silva L, Voetsch B, et al. Cerebral venous thrombosis: influence of risk factors and imaging findings on prognosis. Clin Neurol Neurosurg. 2005;107(5):371-8 Available from: https://www.sciencedirect.com/science/article/pii/ S0303846704001519?via\%3Dihub. [cited 2018 Sep 10].

25. Crovetto F, Ossola MW, Spadaccini G, Duiella SF, Somigliana E, Fedele L. Ischemic stroke recurrence during pregnancy: a case series and a review of the literature. Arch Gynecol Obstet. 286(3):599-604 Available from: http:// www.ncbi.nlm.nih.gov/pubmed/22546951. [cited 2018 May 30].

26. Gastrich MD, Gandhi SK, Pantazopoulos J, Zang EA, Cosgrove NM, Cabrera J, et al. Cardiovascular outcomes after preeclampsia or eclampsia complicated by myocardial infarction or stroke. Obstet Gynecol. 2012;120(4):823-31 Available from: http://insights.ovid.com/crossref?an=00006250-20121000000014. [cited 2018 Sep 3.

27. Ciron J, Godenèche G, Vandamme X, Rosier M-P, Sharov I, Mathis S, et al. Obstetrical outcome of young women with a past history of cerebral venous thrombosis. Cerebrovasc Dis. 2013 Jun;36:55-61.

28. van Alebeek ME, de Vrijer M, Arntz RM, Maaijwee NAMM, Synhaeve NE, Schoonderwaldt $\mathrm{H}$, et al. Increased Risk of Pregnancy Complications After Stroke. Stroke. 2018;49(4):877-83 Available from: http://www.ncbi.nlm.nih. gov/pubmed/29511129. [cited 2018 May 30].

29. Mehraein S, Ortwein H, Busch M, Weih M, Einhäupl K, Masuhr F. Risk of recurrence of cerebral venous and sinus thrombosis during subsequent pregnancy and puerperium. J Neurol Neurosurg \&amp;amp; Psychiatry. 2003; 74(6):814 Available from: http://jnnp.bmj.com/content/74/6/814.abstract.

30. Ertresvg MJ, Stovner LJ, Kvavik E, Johnsen H-J, Zwart J-A, Helde G, et al. Migraine aura or transient ischemic attacks? A five-year follow-up casecontrolstudy of women with transient central nervous system disorders in pregnancy. 2007 [cited 2018 Sep 10]; Available from: http://www. biomedcentral.com/1741-7015/5/19

31. Aguiar de Sousa D, Canhão P, Crassard I, Coutinho J, Arauz A, Conforto A, et al. Safety of Pregnancy After Cerebral Venous Thrombosis. Stroke. 2017;48(11):3130- 
3 Available from: http://stroke.ahajournals.org/lookup/doi/10.1161/STROKEAHA. 117.018829. [cited 2018 Sep 5].

32. Ammon Avalos L, Galindo C, Li D-K. A systematic review to calculate background miscarriage rates using life table analysis. Birth Defects Res Part A Clin Mol Teratol. 2012;94(6):417-23 Available from: http://www.ncbi.nlm. nih.gov/pubmed/22511535. [cited 2018 Oct 17].

33. Sedgh G, Bearak J, Singh S, Bankole A, Popinchalk A, Ganatra B, et al. Abortion incidence between 1990 and 2014: global, regional, and subregional levels and trends. Lancet. 388(10041):258-67 Available from: http://www.ncbi.nlm.nih.gov/pubmed/27179755. [cited 2018 Oct 17].

34. Cruz-Herranz A, Ilán-Gala I, Martínez-Sánchez P, Fuentes B, Díez-Tejedor E. Recurrence of stroke amongst women of reproductive age: impact of and on subsequent pregnancies. Eur J Neurol [Internet]. 2015;22(4):681-e42 Available from: http://doi.wiley.com/10.1111/ene.12630. [cited 2018 Sep 4.

35. Fischer-Betz R, Specker C, Brinks R, Schneider M. Pregnancy outcome in patients with antiphospholipid syndrome after cerebral ischaemic events: an observational study. Lupus. 2012;21(11):1183-9 Available from: https:// doi.org/10.1177/0961203312451335.

36. Soriano D, Carp H, Seidman DS, Schiff E, Langevitz P, Mashiach S, et al. Management and outcome of pregnancy in women with thrombophylic disorders and past cerebrovascular events. Acta Obstet Gynecol Scand. 2002;81(3):204-7 Available from: http://www.ncbi.nlm.nih.gov/pubmed/ 11966475. [cited 2018 May 30].

37. Hindfelt B, Nilsson O. Long-term prognosis of ischemic stroke in young adults. Acta Neurol Scand. 1992;86(5):440-5 Available from: http://www.ncbi. nlm.nih.gov/pubmed/1481624. [cited 2018 Sep 11].

38. Varona JF, Bermejo F, Guerra JM, Molina JA. Long-term prognosis of ischemic stroke in young adults. J Neurol. 2004;251(12):1507-14 Available from: http://www.ncbi.nlm.nih.gov/pubmed/15645352. [cited 2018 May 29].

39. Putaala J, Curtze S, Hiltunen S, Tolppanen H, Kaste M, Tatlisumak T. Causes of death and predictors of 5-year mortality in young adults after first-ever ischemic stroke: the Helsinki young stroke registry. Stroke. 2009;40(8):2698703 Available from: http://www.ncbinlm.nih.gov/pubmed/19590052. [cited 2018 May 29].

Ready to submit your research? Choose BMC and benefit from:

- fast, convenient online submission

- thorough peer review by experienced researchers in your field

- rapid publication on acceptance

- support for research data, including large and complex data types

- gold Open Access which fosters wider collaboration and increased citations

- maximum visibility for your research: over $100 \mathrm{M}$ website views per year

At $\mathrm{BMC}$, research is always in progress.

Learn more biomedcentral.com/submissions 